Send your letters to the Editor, British Dental

Journal, 64 Wimpole Street, London W1G 8YS

E-mailbdj@bda-dentistry.org.uk

Priority will be given to letters less than 500

words long. Authors must sign the letter,

which may be edited for reasons of space. guidelines. It has become apparent to us that the haematologists in the North West were not following these guidelines and in the majority of cases had taken patients off warfarin 48 hours before most oral surgery procedures. Following some discussion with our haematology colleagues on this matter, they had a meeting under the chairmanship of Virginia Clough, who also I gather played a leading role in the Haematology Working Group that referred information to the North West Medicines Information Centre prior to the production of these guidelines.

Overall our haematology colleagues are not in agreement with the guidelines and felt that it was perfectly safe for patients to have an INR between 2.0 and 2.5 but in the majority of the cases, felt that the INR could easily be reduced to 1.5 to 2.0 without any subsequent problems. They would appear, therefore, to not agree with the recommended guidelines as issued by the North West Medicines Information Centre. think our colleagues in general dental practice in the North West should be made aware of the opinion of the haematologists in this region and should not be following the guidelines as recommended by the North West Medicines Information Centre. R. E. Lloyd Salford

Simon Carruthers, Chairman BDA Formulary Committee, responds:The issue of warfarin and primary care dental surgical procedures has been considered by the BDA's Dental Formulary Committee. It is the view of the Committee that the established guidance in this matter, as promulgated by the North West Medicines Information Centre in July $2001^{1}$ and in the Dental Practitioners' Formulary, ${ }^{2}$ rests on a sound evidence base and should be adhered to by all dentists.

Patients who require dental surgical procedures in primary care and who have an INR below 3.0 should continue warfarin therapy without dose adjustment. ${ }^{+}$In these circumstances, bleeding is easily treated with local measures. The risk of thromboembolism after withdrawal of warfarin therapy greatly outweighs the risk of bleeding.
1. www.ukminhs.uk/med info/documents/Dental Patient_on_Warfarin.pdf

2. Dental Practitioners' Formulary 2002-2004. London: BDA, BMA, RPSGB. pp D8, 117-119.

†The October 2002 Dental Practitioners' Formulary gives a threshold INR of 3.0; this supersedes the figure 4.0 given in the North West Medicines Information Centre guidance in July 2001.

\section{Restorations omitted from oral health scoring system}

Sir,- I was interested in the paper Evaluation of an oral health scoring system by dentists in general dental practice (BDJ 2003; 194: 215-218).

It seems to me, on the information given, that there is a glaring gap in the criteria used for the oral health assessment. According to Table 1 the presence and extent of existing restorations appears not to play a part in the scoring system apart from where recurrent caries is recorded.

However skilfully performed, the placing of a restoration in itself creates an increased risk of future dental problems and must be considered to compromise the patient's oral health. Even small fillings greatly raise the chances of tooth fracture and deep fillings, crowns and bridges are well known to increase the risk of pulpitis and pulp necrosis leading to root canal treatment or extraction.

In general practice today problems caused by the failure and limitations of previous restorative work have now outstripped the problems caused by primary caries. I am astonished that any oral health scoring system could pay so little heed to this factor.

Could this glaring omission be due to a mind set in which a filling is regarded as a perfect 'restoration' which implies a tooth is restored to its original healthy condition? An adequately filled tooth is therefore as healthy as an unfilled one. This is clearly nonsense. We should drop the term 'restoration' completely. A more realistic description would be 'repair'.

D. Reekie

Herne Bay 
The authors respond: We thank Dr Reekie for his comments. The Oral Health Score and its precursor the Oral Health Index are intended to provide a snapshot of the state of a patient's mouth at the time of examination. They are not intended to provide any estimates of the patient's future dental problems. We acknowledge that large cavities and restorations may predispose to tooth fracture ${ }^{1}$ but we do not agree that small fillings 'greatly raise' the chance of tooth fracture. We agree that a perfect restoration does not restore a tooth to its original healthy state. Nevertheless, the score does reflect failing restorations against the criteria set by Ryge $e^{2}$ and SAMS ${ }^{3}$.

We feel that the addition of factors which would estimate the chance of failure of a restoration would unnecessarily complicate a scoring system which has recently undergone reproducibility tests which were satisfactory ${ }^{4}$. To our knowledge, only one index, the Tissue Health Index (THI) in 1987, has attempted to weight the relative amounts of sound tissue in teeth ${ }^{5}$, and this has not yet found use.

\section{F. J. T. Burke, M. Busby, R. Matthews,}

S. McHugh, A. Mullins.

1 Burke FJ.T. Tooth fracture in vivo and in vitro: A review. J. Dent 1992: 20: 131-139.

2 Ryge G. Clinical criteria. Int Dent. J 1980 30: 347-357.

3 Advisory Board in General Dental Practice. Self assessment manual and standards.

London: Royal College of Surgeons of England 1991.

4 Busby M, Delargy S, McHugh S, Matthews R, Burke F.J.T. Reproducibility of an Oral Health Score among general dental practitioners. PEF IADR Abs. No.417, Sept 2002.

5 Sheiham A, Maizels J, Maizels A. New composite indicators of dental health. Comm Dent Health 1987: 4: 407-414.

\section{Do-it-yourself dentistry}

Sir,- Lost anterior teeth can be a real aesthetic problem for patients, and are now typically substituted by removable dentures, bridges or implants placed by professionals. However, in most circumstances, and particularly where professional dental care is accessible, do-ityourself (DIY) dental treatment would usually be regarded as at the very least, inappropriate. We recently saw a bizarre case where a 63-year-old Brazilian male patient, a heavy smoker, consuming two packs of cigarettes a day for 45 years, and a very poorly controlled diabetic presented with severe periodontitis. Examination revealed PVC-type plastic strips each carrying the crowns of three natural teeth and bent to adapt to the dental arches, fixed with superbond to the palatal and lingual surfaces of the canines, rather along the lines of Maryland bridges (Figures 1 and 2).

Having extracted his own maxillary and mandibular incisors, he had constructed the bridges by removing the crowns from the roots of his own newly-extracted teeth with a saw. Though the patient could not use the bridges for mastication, and the devices needed to be recemented daily, he was otherwise quite happy with the aesthetics. He chewed mainly on his canines and on his posterior alveolar ridges, the remaining standing upper premolars on each side and one standing upper left molar. The mandibular posterior alveolar ridges were irregularly white, due to frictional keratosis caused by the trauma of mastication.

The patient was of a low income group, and in such instances, or where access to dental professional care is difficult, the need for self-care (DIY) can be readily appreciated. In the distant past however, devices were sometimes constructed by the patient or by non-professionals, but nowadays these self-made devices are rare, as in this instance. Though many clinicians will have encountered patients who carried out such DIY procedures such as the occasional selfextraction, denture or appliance adjustments and relines, denture and tooth repairs, and particularly tooth-whitening, there are surprisingly few formal reports of such DIY dentistry in the literature. Reports include the self-adjustment of a partial prosthesis where the remaining standing teeth had been lost ${ }^{1}$, and self-extraction of teeth $^{2}$. Others have commented on the selfre-cementing of prostheses and the possible disadvantages and even occasional dangers of such DIY dentistry, such as the inhalation of material ${ }^{3,4}$.

\section{O. Di Hipolito, M. Ajudarte Lopes, O. Paes de} Almeida, Brazil

1. Jagger D C,.Harrison A. DIY dentures - a case report. $B r$ Dent J1996; 180: 221-2.

2. Ring M E. Do-it-yourself dentistry. Bull Hist Dent 1993; 41:33-4.

3. Granstrom G. Upper airway obstruction caused by a do-it-yourself denture reliner. J Prosthet Dent 1990; 63: 495-6.

4. Getz II. The dangers of do-it-yourself dentistry. Gen Dent 1987; 35: 361-2.

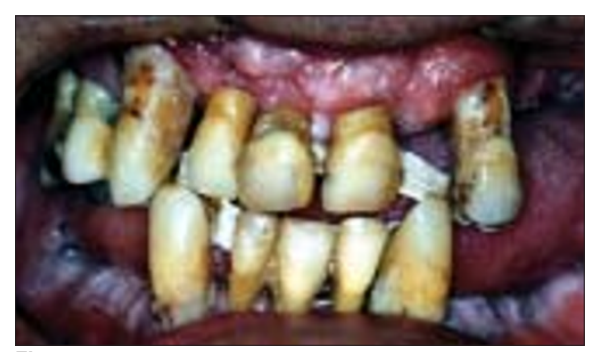

Figure 1

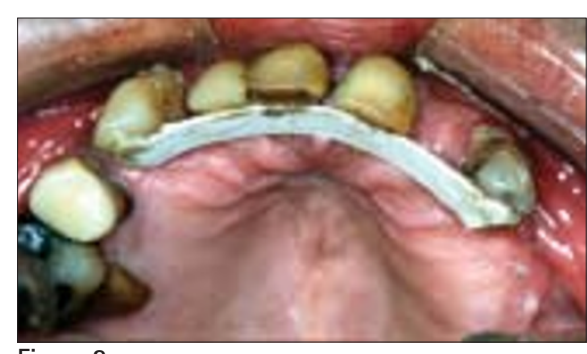

